EGU2020-21793

https://doi.org/10.5194/egusphere-egu2020-21793

EGU General Assembly 2020

(c) Author(s) 2021. This work is distributed under

the Creative Commons Attribution 4.0 License.

\title{
On the role of cave-soil in the carbon cycle. A fist approach.
}

\author{
Soledad Cuezva ${ }^{1}$, Tamara Martin-Pozas ${ }^{2}$, Angel Fernandez-Cortes ${ }^{3}$, Juan Carlos Canaveras ${ }^{4}$, Ivan \\ Janssens ${ }^{1}$, and Sergio Sanchez-Moral ${ }^{2}$ \\ ${ }^{1}$ University of Antwerp, Department of Biology, Research group Plants and Ecosystems, Belgium \\ ${ }^{2}$ National Museum of Natural Sciences, MNCN-CSIC, Spain \\ ${ }^{3}$ University of Almeria, Research group Water Resources and Environmental Geology, Spain \\ ${ }^{4}$ University of Alicante, Spain.
}

Karsts cover up to $25 \%$ of the land surface and contain significant sedimentary deposits that become active cave-soils. Subterranean karst ecosystems play an active role in the global carbon cycle in terms of their contribution to the global GHG balance. They act alternately as a source or sink of $\mathrm{CO}_{2}$ and as a rapid sink of $\mathrm{CH}_{4}$. The most recent results indicate that microbiota must play a significant ecological role in the biogeochemical processes that control the subterranean atmosphere composition. Soils forming underneath the surface must host a large part of the subterranean microbiota. But to date, their behaviour concerning the production of gases and exchange with the "confined troposphere" has not been evaluated. Systematic direct estimates of $\mathrm{CO}_{2}$ and $\mathrm{CH}_{4}$ fluxes from cave-soils do not exist in literature. And they are needed before global generalizations can be made about the carbon budgets (emissions and sinks) of karstic ecosystems.

Here we present pioneering research to evaluate the carbon fluxes from the cave soils directly exchanged with the cave atmosphere. This preliminary study is the first approach to systematically characterize the role of cave-soils in the production and transport of $\mathrm{CO}_{2}$ and $\mathrm{CH}_{4}$ in the subterranean environment. We carried out automatic in situ and real-time monitoring of $\mathrm{CO}_{2}$ and $\mathrm{CH}_{4}$ diffusive fluxes from a sedimentary alluvial soil in Pindal cave for one year (north Spain). We developed seasonal campaigns for $\mathrm{CH}_{4}$ and $\mathrm{CO}_{2}$ fluxes daily continuous monitoring by a LICOR closed chamber-based gas exchange system, in conjunction with a compatible Gasmet FTIR gas analyser. Moreover, autonomous equipment monitored the main micro-environmental parameters of the local subsurface-soil-atmosphere system. To interpret gas exchange processes and rates, and to understand the underlying mechanisms in soils, we also carried out seasonal $\delta^{13} \mathrm{C}$ geochemical tracing by using Picarro cavity ring-down spectroscopy, through simultaneous cave atmosphere-soil-chamber air samplings. We also characterized the soil microbial communities related to the carbon cycle by meta-barcoding analyses of bacterial 16S rRNA genes and Shotgun Metagenomics.

Preliminary results show net $\mathrm{CO}_{2}$ emissions from cave-soil on a daily scale, resulting from respiration by chemotrophic microorganisms. We detect significant magnitude variations along the day, reaching occasionally values close to zero. This is remarkable in such thermo-hygrometric 
stable environment and absence of light. Changes in the cave ventilation regime seems to be the determining factor just in some cases. Intrinsic microbial processes appear to be decisive in others. The results also reveal net $\mathrm{CH}_{4}$ uptake from cave-soil on a daily scale, with no significant magnitude variations along the day. It seems to be linked to the metabolism of Nitrate-dependent methanotrophs belonging to the phylum Rokubacteria. Additionally, we detected significant variations in magnitude and different flow patterns in the cave-soils colonized by biofilms, most prominent in the case of moonmilk deposits.

These preliminary results confirm that cave-soil is playing an outstanding role in the processes of production, consumption and storage of $\mathrm{CO}_{2}$ and $\mathrm{CH}_{4}$ and may be partially determining the strong variations of these major GHGs in natural subterranean ecosystems. 